\title{
Quantitative proteomic analysis of the miR-148a-associated mechanisms of metastasis in non-small cell lung cancer
}

\author{
DANDAN CHU* ${ }^{*}$ JING LI* ${ }^{*}$ HECHUN LIN, XIAO ZHANG, HONGYU PAN, \\ LEI LIU, TAO YU, MINGXIA YAN and MING YAO
}

\begin{abstract}
State Key Laboratory of Oncogenes and Related Genes, Shanghai Cancer Institute, Renji Hospital, Shanghai Jiao Tong University School of Medicine, Shanghai 200032, P.R. China
\end{abstract}

Received December 14, 2016; Accepted October 13, 2017

DOI: $10.3892 / \mathrm{ol} .2018 .8581$

\begin{abstract}
MicroRNAs (miRs) are small non-coding RNAs that regulate gene expression and protein synthesis. Our previous study demonstrated that miR-148a suppressed the metastasis of non-small cell lung cancer (NSCLC) in vitro and in vivo. However, the modulatory mechanism of this effect remains unclear. In the present study, quantitative proteomic technology was used to study the protein expression profile of SPC-A-1 cells subsequent to the downregulation of miR-148a expression, in order to elucidate the molecular mechanism of the suppression of NSCLC metastasis by miR-148a. The differentially expressed proteins identified were analyzed using bioinformatics tools, including the Database for Annotation, Visualization and Integrated Discovery and the Search Tool for the Retrieval of Interacting Genes/proteins. In two experiments, 4,048 and 4,083 proteins were identified, and 4,014 and 4,039 proteins were quantified, respectively. In total, 44 proteins were upregulated and 40 proteins were downregulated. This was verified at the protein and mRNA levels by western blotting and reverse transcription-quantitative polymerase chain reaction, respectively. Bioinformatics analysis was used to identify potential interactions and signaling networks for the differentially expressed proteins. This may have provided an appropriate perspective for the comprehensive analysis of the modulatory mechanism underlying the metastasis-suppressive effects of miR-148a in NSCLC. In conclusion, quantitative proteomic technology revealed that miR-148a may regulate a panel of tumor-associated proteins to suppress metastasis in NSCLC.
\end{abstract}

Correspondence to: Dr Mingxia Yan or Dr Ming Yao, State Key Laboratory of Oncogenes and Related Genes, Shanghai Cancer Institute, Renji Hospital, Shanghai Jiao Tong University School of Medicine, 25/Ln 2200, Xietu Road, Shanghai 200032, P.R. China

E-mail: mingxia_yan@126.com

E-mail: myao@shsci.org

*Contributed equally

Key words: microRNA-148a, proteomic, non-small cell lung cancer, metastasis, bioinformatics analysis

\section{Introduction}

Lung cancer is the leading cause for cancer-associated mortality worldwide $(1,2)$. Despite considerable improvements in diagnosis and chemotherapy, and the development of molecularly-targeted treatments, the survival rate for lung cancer remains low; the 5-year survival rate is $<20 \%$ (3). Non-small cell lung cancer (NSCLC) is responsible for $>80 \%$ of the cases of lung cancer-associated mortality (4). One reason for the poor prognosis of lung cancer is metastasis, which presents a major challenge in the treatment of NSCLC (5). To overcome this challenge, the elucidation of the molecular mechanism underlying NSCLC metastasis is required.

MicroRNAs (miRNAs) are small non-coding RNAs that negatively regulate the translation of mRNA or induce target gene mRNA degradation (6,7). Accumulating evidence suggests that miRNAs are associated with a number of cellular biological processes, including proliferation, apoptosis, drug resistance and metastasis. Regarding the role of miRNAs in cancer, a number of potential therapeutic targets were previously identified (8-10). The mechanisms underlying the effects of miRNAs is a longstanding research topic, and a number of studies have aimed to identify the target signaling pathways of cancer-associated miRNAs $(11,12)$.

Proteomics is an emerging field that offers a wide range of opportunities to investigate the malignancy-associated molecular alterations at the protein level, and is thus being increasingly applied in cancer research (13). Isobaric labeling reagents are peptide tags that produce tandem mass spectrometry (MS/MS) spectrum-specific fragment ions, used for MS/MS quantification (14). Isobaric Tag for Relative and Absolute Quantitation (iTRAQ) labeling technology combined with nano liquid chromatography-mass spectrometry (NanoLC-MS/MS) has been employed effectively for biomarker discovery (15). As miRNAs not only induce alterations of the protein expression level of their target genes, but also indirectly change the expression of a range of proteins through interactions with target proteins, cancer research is turning to proteomics-based strategies to seek the putative targets and further molecular mechanisms modulated by miRNAs (16-18).

Our previous study (19) demonstrated that miR-148a exerted metastasis-suppressive effects on NSCLC. However, the molecular mechanisms underlying the 
metastasis-suppressive effects of miR-148a on NSCLC remain uncharacterized. In the present study, iTRAQ labeling technology and NanoLC-MS/MS were used to analyze the whole protein profiles of SPC-A-1 lung adenocarcinoma cells following transfection with the miR-148a inhibitor. The data may provide a general perspective for the analysis of the metastasis-modulatory mechanism of miR-148a in NSCLC.

\section{Materials and methods}

Cell lines and cell culture. SPC-A-1 human lung adenocarcinoma cells were obtained from the Cellular Institute of the Chinese Academy of Science (Shanghai, China). The SPC-A1 cells were cultured in Dulbecco's modified Eagle's medium (DMEM; Hyclone; GE Healthcare Life Sciences, Logan, UT, USA) supplemented with $10 \%$ fetal bovine serum (Biowest, Nuaillé, France), $100 \mathrm{U} / \mathrm{ml}$ penicillin sodium and $100 \mathrm{mg} / \mathrm{ml}$ streptomycin sulfate at $37^{\circ} \mathrm{C}$ in a humidified atmosphere containing $5 \% \mathrm{CO}_{2}$.

Oligonucleotide transfection. An miR-148a inhibitor (miR20000243) and negative control (miR02101-1-5) were synthesized by Guangzhou RiboBio Ltd. (Guangzhou, China). On day $1,5 \times 10^{4}$ cells were seeded into a 6 -well plate and were transfected on day 2 with the miRNA inhibitor or a control oligonucleotide using Lipofectamine ${ }^{\circledR} 2000$ (Invitrogen; Thermo Fisher Scientific, Inc., Waltham, MA, USA), according to the manufacturer's instructions. Cells were collected at $48 \mathrm{~h}$ after transfection for RNA extraction and protein preparation.

$R N A$ extraction and reverse transcription-quantitative polymerase chain reaction ( $R T-q P C R)$ assays. miRNA was extracted from the transfected cells using a mirVana miRNA Isolation kit (Ambion, Thermo Fisher Scientific, Inc.). The expression level of mature miR-148a was quantified with specific primers (Guangzhou RiboBio Ltd.) according to the manufacturer's instructions. RT-qPCR was performed using miRNA RT-qPCR Starter kit (Guangzhou RiboBio Ltd.) and normalized to U6 small nuclear RNA. U6 primers were synthesized in Guangzhou RiboBio Ltd. The $\mathrm{RT}$ reaction conditions were as follows: $42^{\circ} \mathrm{C}$ for $60 \mathrm{~min}, 70^{\circ} \mathrm{C}$ for $10 \mathrm{~min}$. The PCR was conducted based on following conditions: pre-denaturation at $95^{\circ} \mathrm{C}$ for $10 \mathrm{~min}$, followed by 40 cycles of denaturation at $95^{\circ} \mathrm{C}$ for $2 \mathrm{sec}$, annealing at $60^{\circ} \mathrm{C}$ for $20 \mathrm{sec}$, and extension at $70^{\circ} \mathrm{C}$ for $10 \mathrm{sec}$.

Total RNA was extracted from transfected cells using TRIzol (Invitrogen; Thermo Fisher Scientific, Inc.) according to the manufacturer's instructions, and was quantified using a NanoDrop 2000 spectrophotometer (NanoDrop; Thermo Fisher Scientific, Inc., Wilmington, DE, USA). First-strand cDNA was synthesized with a PrimeScript RT Reagent kit and RT-qPCR was performed with SYBR Green Premix Ex Taq (both from Takara Bio, Inc., Otsu, Japan) using $\beta$-actin as an endogenous control. The primers were synthesized by Genewiz, Inc. (South Plainfield, NJ, USA), and the sequences are presented in the Table I. The RT reaction conditions were as follows: $37^{\circ} \mathrm{C}$ for $45 \mathrm{~min}, 85^{\circ} \mathrm{C}$ for $5 \mathrm{sec}$. While the PCR was conducted based on following conditions: pre-denaturation at $95^{\circ} \mathrm{C}$ for $10 \mathrm{~min}$, followed by 40 cycles of denaturation at $95^{\circ} \mathrm{C}$ for $5 \mathrm{sec}$, annealing and extension at $60^{\circ} \mathrm{C}$ for $31 \mathrm{sec}$.
The relative expression level of miR-148a and differentially expressed gene were analyzed using the comparative Cq method (20).

Protein preparation. All protein extraction procedures were performed on ice. The cell pellets were dissociated in lysis buffer (Pierce; Thermo Fisher Scientific, Inc.) supplemented with protease and phosphatase inhibitors, followed by $40 \mathrm{~min}$ incubation on ice. The lysate was centrifuged at $12,000 \mathrm{x} \mathrm{g}$ for $15 \mathrm{~min}$ at $4^{\circ} \mathrm{C}$, and the supernatants were collected. The protein concentrations were determined using a bicinchoninic acid protein assay kit (Pierce; Thermo Fisher Scientific, Inc.) according to the manufacturer's instructions, using bovine serum albumin (Roche Diagnostics, Basel, Switzerland) as the standard.

iTRAQ labeling. The following iTRAQ experiments were performed as described previously (15), with some modifications. iTRAQ labeling was achieved using an iTRAQ Reagent 4-Plex kit (Applied Biosystems; Thermo Fisher Scientific, Inc.) according to the manufacturer's instructions. The cell lysates of SPC-A1 cells transfected with the control or miR-148a inhibitor were labeled with iTRAQ labeling reagents 116 and 117, respectively. In brief, $100 \mu \mathrm{g}$ lysate from each sample was reduced with tris-(2-carboxyethyl) phosphine, alkylated with methyl methanethiosulfonate (MMTS) and digested overnight at $37^{\circ} \mathrm{C}$ using trypsin (mass spectrometry grade; Promega Corporation, Madison, WI, USA) at a trypsin to protein ratio of 1:20 (w/w). The iTRAQ labeled samples were combined and transferred into a $1.5 \mathrm{ml}$ tube, desalted with Oasis HLB cartridges (Waters Corporation, Milford, MA, USA) and dried in a vacuum centrifuge (Concentrator Plus; Eppendorf, Hamburg, Germany) at $45^{\circ} \mathrm{C}$ for $1 \mathrm{~h}, 60^{\circ} \mathrm{C}$ for 1 to $2 \mathrm{~h}$. The iTRAQ workflow is illustrated in Fig. $1 \mathrm{~A}$.

Strong cation exchange (SCX). The iTRAQ-labeled peptides were fractionated by SCX chromatography using a 20AD HPLC system (Shimadzu Corporation, Kyoto, Japan) and a polysulfethyl column $(2.1 \times 100 \mathrm{~mm}, 5 \mu \mathrm{g}, 200 \AA$ A; The Nest Group, Inc., Southborough, MA, USA). The peptide mixture was dissolved in $80 \mu \mathrm{l}$ buffer $\mathrm{A}\left[10 \mathrm{mM} \mathrm{KH} \mathrm{PO}_{4}\right.$ in $25 \%$ acetonitrile (ACN; pH 3.0); Thermo Fisher Scientific, Inc.] and loaded onto the column. The peptides were separated in a gradient of $0-80 \%$ buffer $\mathrm{B}$ (as buffer $\mathrm{A}$, with the addition of $350 \mathrm{mM} \mathrm{KCl}$ ) at a flow rate of $200 \mu \mathrm{l} / \mathrm{min}$ over $60 \mathrm{~min}$. A total of $20 \mathrm{RP}$ fractions were collected, desalted using C18 cartridges (UltraMicroSpin; The Nest Group, Inc.), dried and reconstituted using $20 \mu 10.1 \%$ formic acid (FA) for NanoLC-MS/MS analysis.

NanoLC-MS/MS analysis. A NanoLC system (NanoLC-2D Ultra; Eksigent Technologies, Dublin, CA, USA) combined with a Triple TOF 5600 mass spectrometer (AB Sciex LLC, Framingham,MA, USA) were utilized for analysis. The peptides were enriched on a reversed-phase trap column (ProteoPepII C18 column, $5 \mu \mathrm{m}, 300 \AA, 0.15 \times 25$ mm; New Objective IntegraFrit; Scientific Instrument Services, Inc., Ringoes, NJ, USA) and eluted onto an analytical column (ProteoPep C18 column, $5 \mu \mathrm{m}, 300 \AA$, $0.075 \times 150 \mathrm{~mm}$; New Objective IntegraFrit; Scientific Instrument Services, Inc.). The NanoLC 
Table I. Primer sequences used in experiments.

\begin{tabular}{lll}
\hline Genes & \multicolumn{1}{c}{ Forward } & Reverse \\
\hline MYH9 & GACAGCCAGAGCGTTAGAGG & AGACCAGTGAGGACGAGCTA \\
CD44 & CCTCCCTCCGTCTTAGGTCA & ATTCAAATCGATCTGCGCCA \\
ITGB1 & CCGCGCGGAAAAGATGAAT & ATGTCATCTGGAGGGCAACC \\
LAMB3 & GGGAGACCCCCACATTCAAG & GCAGGGCAAAACACAAGAGG \\
PHGDH & CTGGCCAGGCAGATTCCC & AGAGGCCAGATCTCCTCCAG \\
ACTN4 & TGACAAGCTGAGGAAGGACG & ATTATGGCCTTCTCGTCGGG \\
LMNA & ATCGCTTGGCGGTCTACATC & TTGGTATTGCGCGCTTTCAG \\
VIM & GGACCAGCTAACCAACGACA & AAGGTCAAGACGTGCCAGAG \\
PSMA7 & GTGTGCGCTTTTGAGAGTCG & TCTTCCTCGAACACCAACCG \\
MTHFD1 & TCCAGTAGTAGTGGCCGTGA & GCTTTGTGTGAGCTTCGGG \\
GSTM3 & TGCACAGTTGGAGAGAGCAG & TGTACACAGGACGGTTTCCG \\
FH & AGCCGCCCAGAAATTCTACC & TTTTGGCTTGCCATTCGAGC \\
HSPB1 & CGCGGAAATACACGCTGC & CGGATTTTGCAGCTTCTGGG \\
LRPPRC & TGGCCGGAGGACTACTGAG & GCAAGGCATGACTACCACCT \\
CPT2 & AAGAAGCAGCAATGGGCCAG & AGGGTCCAGGTAGAGCTCAG \\
IDH2 & TTTGCAACGCCATAGGCTTC & CTCATCAGGGGTGATGGTGG \\
-actin & TTGTTACAGGAAGTCCCTTGCC & ATGCTATCACCTCCCCTGTGTG \\
\hline
\end{tabular}

gradient was $5-35 \%$ buffer $\mathrm{C}\left(98 \% \mathrm{ACN}, 2 \% \mathrm{H}_{2} \mathrm{O}, 0.1 \%\right.$ FA) over $120 \mathrm{~min}$ at a flow rate of $300 \mathrm{nl} / \mathrm{min}$. The MS analysis was performed in the positive-ion mode with a nano ion spray voltage being typically maintained at $2.3 \mathrm{kV}$ and a scan range of 350 to $1,500(\mathrm{~m} / \mathrm{z})$. Full-scan MS spectra were acquired from 40 precursors selected for MS/MS from the $100-1,500 \mathrm{~m} / \mathrm{z}$ range, utilizing a dynamic exclusion of $30 \mathrm{sec}$. The IDA collision energy (CE) parameter script, selecting up to 40 precursors with charge states of $2^{+}$to $4^{+}$, controlled the $\mathrm{CE}$ automatically. The tryptic peptides of $\beta$-galactosidase were used to calibrate the mass spectrometer.

Protein identification and quantification. Analysis of the proteins was performed using ProteinPilot 4.1 software (AB Sciex). The search parameters were specified as follows: i) Sample type, iTRAQ 4-plex (peptide-labeled); ii) cysteine alkylation, MMTS; iii) digestion, trypsin; iv) instrument, TripleTOF 5600; v) special factors, none; vi) species, Homo sapiens; vii) ID Focus, biological modifications; viii) database, UniProtKB/Swiss-Prot FASTA (as released in November 2013 with 176,592 human sequences); and ix) search effort, thorough ID. The peptides for iTRAQ quantitation were automatically chosen by the Pro Group ${ }^{\mathrm{TM}}$ algorithm from the ProteinPilot software to calculate the reporter peak area and the false discovery rate (FDR) using a reverse database search strategy. A qualification criterion of unused confidence score $>1.3$ was enforced, corresponding to a peptide confidence level of $95 \%$. When the iTRAQ ratios were $>1.5$ or $<0.67$ between the SPC-A-1 cells transfected with the control $\mathrm{miR}$ and with the $\mathrm{miR}-148 \mathrm{a}$ inhibitor, the protein expression levels were considered to be differential.

Western blotting (WB). A total of $20 \mu \mathrm{g}$ of protein samples from the collected cells were loaded onto 8-12\% SDS-PAGE gels and transferred onto nitrocellulose filter membranes
(EMD Millipore, Billerica, MA, USA). Subsequent to blocking $\left(20^{\circ} \mathrm{C}\right.$ for $\left.1 \mathrm{~h}\right)$ in $5 \%$ non-fat milk in PBS, the membranes were incubated overnight at $4^{\circ} \mathrm{C}$ with rabbit primary antibodies against the following: DNA methyltransferase 1 (DNMT1, dilution 1:500, D160261), matrix metallopeptidase 15 (MMP15, 1:500 dilution, D120991), Rho-associated protein kinase 1 (ROCK1, 1:1,000 dilution, D221198), sphingosine-1-phosphate receptor 1 (S1PR1, 1:500 dilution, D161195), cholecystokinin B receptor (CCKBR, 1:500 dilution, D160389), WNT1 (1:200 dilution, D261302), (MMP7, 1:500 dilution, D120096), actinin $\alpha 4$ (ACTN4, 1:500 dilution, D221929), fumarate hydratase (FH, 1:500 dilution, D222390), heat shock protein $\beta 1$ (HSPB1, 1:500 dilution, D163024), lactate dehydrogenase (LDHB, 1:1,000 dilution, D151002), fatty acid synthase (FASN, 1:200 dilution, D190620) and catalase (CAT, 1:500 dilution, D122036) (all from BBI Life Sciences Corporation, Shanghai, China), vimentin (VIM, 1:200 dilution, sc-5565) and laminin $\beta 3$ (LAMB3, 1:200 dilution, sc-20775) (both from Santa Cruz Biotechnology, Inc., Dallas, TX, USA), phosphoglycerate dehydrogenase (PHGDH; 1:200 dilution, AP2936c; Abgent, San Diego, CA, USA) and isocitrate dehydrogenase $\left(\mathrm{NADP}^{+}\right) 2$ (IDH2, 1:200 dilution, ab131263; Epitomics, Burlingame, CA, USA).

HRP-conjugated anti-rabbit IgG (1:5,000 dilution, A0545; Sigma-Aldrich; Merck KGaA, Darmstadt, Germany) was used as the secondary antibody in which membranes were incubated at $20^{\circ} \mathrm{C}$ for $2 \mathrm{~h}$. A total of 3 washes in PBS-Tween were performed following each antibody incubation. SuperSignal West Femto Maximum Sensitivity substrate (Thermo Fisher Scientific, Inc.) was used for the visualization of the proteins, and $\beta$-actin was used as a loading control (1:30,000 dilution, A3854; Sigma-Aldrich, Merck KGaA).

Statistical analysis. The differentially expressed proteins were input into the Database for Annotation, Visualization 
A

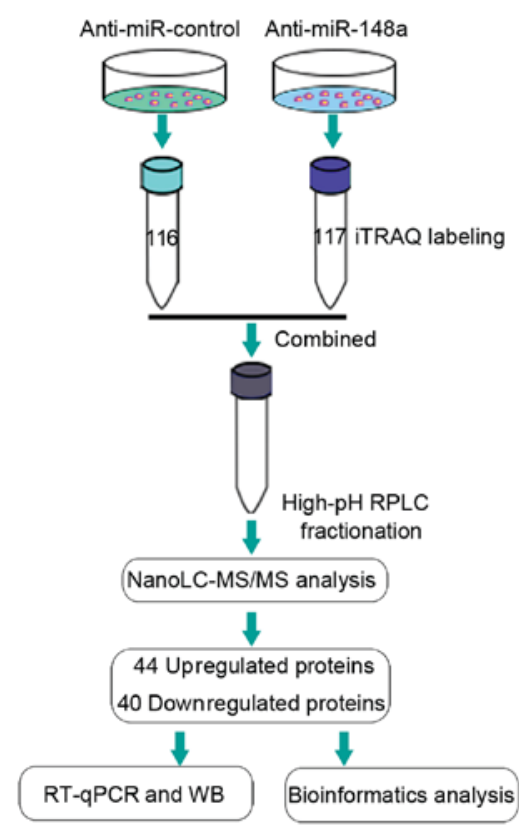

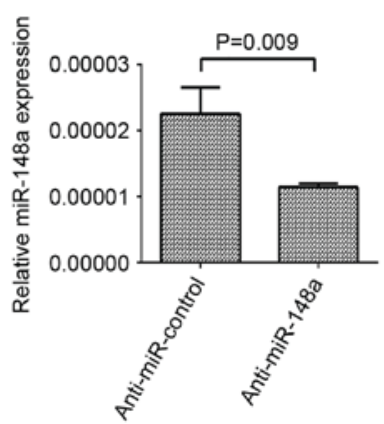

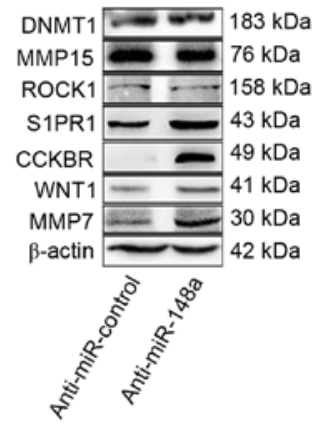

Identification

Quantification

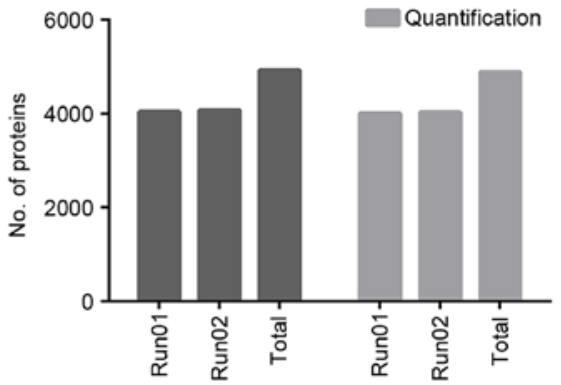

Figure 1. Quantitative proteomic analysis experimental workflow and results. (A) SPC-A-1 cells were transfected with a miR-148a inhibitor or a control oligonucleotide. At $48 \mathrm{~h}$, proteins of the transfected cells were digested with trypsin and labeled with the iTRAQ tags 116 and 117 . The labeled peptides were then separated using offline strong cation exchange LC and analyzed using NanoLC-MS/MS. The experiment was performed in duplicate, and identified 44 upregulated/40 downregulated proteins, for a total of 84 differentially expressed proteins, which were then analyzed with bioinformatics. A number of the differentially expressed proteins were also verified with WB and RT-qPCR. (B) RT-qPCR quantification of miR-148a in the SPC-A-1 cells at $48 \mathrm{~h}$ after transfection. (C) Expression levels of miR-148a-associated proteins as determined by WB in the SPC-A-1 cells at $48 \mathrm{~h}$ after transfection, to demonstrate the downregulation of miR-148a at the functional level. $\beta$-actin served as an internal control. (D) Across the two MS experiments, a total of 4,934 proteins were identified, and 4,885 proteins were quantified, with the criteria of an unused protein score $>1.3$ and a number of peptides $\geq 2$. The label rate was $99.0 \%$ $(4,885 / 4,934)$. miR, microRNA; iTRAQ, isobaric tag for relative and absolute quantitation; LC, liquid chromatography; MS, mass spectrometry; WB, western blotting; RT-qPCR, reverse transcription-quantitative polymerase chain reaction; DNMT1, DNA methyltransferase 1; MMP15, matrix metalloproteinase 15; ROCK1, Rho associated protein kinase 1; S1PR1, sphingosine 1-phosphate receptor 1; CCKBR, cholecystokinin B receptor; MMP7, matrix metalloproteinase 7.

and Integrated Discovery (DAVID; http://david.abcc.ncifcrf .gov/) and the Search Tool for the Retrieval of Interacting genes/proteins (STRING; http://string.embl.de). The DAVID search tool was used for the Gene Ontology (GO) term and Kyoto Encyclopedia of Genes and Genomes (KEGG) pathway analysis of the differentially expressed proteins, with a threshold of $\mathrm{P}<0.05$. STRING was used to predict protein-protein interactions with a weight score threshold of $\leq 0.4$.

Statistical analysis. t-tests performed with SPSS 19.0 software (IBM Corp., Armonk, NY, USA) were used to analyze differences between the protein profiles, the level of miR-148a expression and the mRNA expression of the differentially expressed proteins between the cells treated with a miR-148a inhibitor and the control. $\mathrm{P}<0.05$ was considered to indicate a statistically significant difference.

\section{Results}

Quantitative proteomic analysis of miR-148a-regulated downstream proteins. To identify downstream proteins regulated by miR-148a, global protein expression changes in the expression profile of SPC-A-1 cells transfected with a miR-148a inhibitor compared with SPC-A-1 cells transfected with a control oligonucleotide were identified using the iTRAQ-labeling proteomic approach.
The knockdown of miR-148a in SPC-A-1 cells was detected using RT-qPCR (Fig. 1B) and validated at a functional level by performing western blots for 7 well-established targets of miR-148a: DNMT1, MMP15, ROCK1, S1PR1, CCKBR, WNT-1 and MMP7, which were selected according to previous studies (21-26). No evident change was observed for DNMT1, MMP15 or ROCK1, whereas S1PR1, CCKBR, WNT1 and MMP7 expression levels were distinctly upregulated in SPC-A1 cells treated with the miR-148a inhibitor compared with SPC-A-1 cells treated with the control (Fig. 1C).

With the criteria of unused protein score $>1.3$ and number of peptides $\geq 2$, two iTRAQ experiments identified 4,048 and 4,083 proteins, as annotated with ProteinPilot software (global FDR, <1\%), and 4,014 and 4,039 proteins were quantified. Cumulatively, 4,934 proteins were identified and 4,885 proteins were quantified (Fig. 1D); the label rate was $99.0 \%(4,885 / 4,934)$. A total of 44 upregulated and 40 downregulated proteins were identified in the SPC-A-1 cells treated with the miR-148a inhibitor compared with the control cells $(\mathrm{P}<0.05$; Table II).

Cluster analysis of miR-148a-regulated downstream proteins. A heat map was generated for the 84 differentially expressed proteins subsequent to miR-148a inhibitor transfection (Fig. 2). The identified differentially expressed 
Table II. Differentially expressed proteins in microRNA-148a inhibitor-transfected cells compared with control cells.

A, Upregulated differentially expressed proteins

\begin{tabular}{|c|c|c|c|c|c|c|}
\hline Accession & Protein & Unused score & Coverage, $\%^{a}$ & Peptide $95 \% \mathrm{CL}^{\mathrm{a}}$ & iTRAQ rate & P-value ${ }^{a}$ \\
\hline splQ09666 & AHNAK & $457.84 \pm 0.62$ & $66.71 \pm 1.69$ & $352.5 \pm 12.02$ & $4.57 \pm 0.18$ & $<0.0001$ \\
\hline splP02545 & LMNA & $91.37 \pm 2.67$ & $66.04 \pm 3.30$ & $75.5 \pm 3.54$ & $9.83 \pm 0.77$ & $<0.0001$ \\
\hline $\operatorname{tr|F5GZS6~}$ & SLC3A2 & $54.32 \pm 0.18$ & $45.74 \pm 0.23$ & $37.5 \pm 0.71$ & $4.45 \pm 0.06$ & $<0.0001$ \\
\hline splO43707 & ACTN4 & $130.18 \pm 3.61$ & $71.84 \pm 4.11$ & $167.5 \pm 7.78$ & $2.54 \pm 0.80$ & $<0.0001$ \\
\hline splP35579 & MYH9 & $222.67 \pm 10.28$ & $59.18 \pm 2.38$ & $319.5 \pm 9.19$ & $1.65 \pm 0.05$ & $<0.0001$ \\
\hline trlE7EPC6 & CD44 & $20.93 \pm 1.51$ & $15.41 \pm 0.38$ & $14.5 \pm 0.71$ & $5.85 \pm 0.19$ & $<0.0001$ \\
\hline splP16615-5 & ATP2A2 & $48.62 \pm 5.43$ & $30.59 \pm 3.83$ & $32.5 \pm 0.71$ & $2.10 \pm 0.18$ & $<0.0001$ \\
\hline splO43175 & PHGDH & $42.32 \pm 4.59$ & $56.01 \pm 6.50$ & $43.5 \pm 4.94$ & $4.43 \pm 1.80$ & 0.0004 \\
\hline splQ07065 & CKAP4 & $37.42 \pm 3.34$ & $37.13 \pm 0.12$ & $23.5 \pm 2.12$ & $1.84 \pm 0.07$ & 0.0084 \\
\hline splP05556 & ITGB1 & $34.97 \pm 1.27$ & $25.50 \pm 0.27$ & $22.5 \pm 3.54$ & $2.35 \pm 0.33$ & 0.0002 \\
\hline splQ9Y6N5 & SQRDL & $33.74 \pm 1.28$ & $44.56 \pm 4.24$ & $20.0 \pm 1.41$ & $2.12 \pm 0.18$ & 0.0007 \\
\hline splQ13501 & SQSTM1 & $31.33 \pm 1.22$ & $63.41 \pm 0.00$ & $25.5 \pm 2.12$ & $4.04 \pm 0.08$ & 0.0002 \\
\hline splP07355-2 & ANXA2 & $75.77 \pm 0.13$ & $72.13 \pm 1.39$ & $135.5 \pm 9.19$ & $1.86 \pm 0.04$ & 0.0012 \\
\hline splP21980 & TGM2 & $46.15 \pm 2.05$ & $45.30 \pm 6.38$ & $30.0 \pm 2.83$ & $2.12 \pm 0.28$ & 0.0002 \\
\hline trlH0Y323 & CAPN2 & $49.09 \pm 2.84$ & $48.01 \pm 5.43$ & $34.5 \pm 3.54$ & $2.39 \pm 1.14$ & 0.0004 \\
\hline trlF5H0Q5 & AHSG & $8.43 \pm 0.08$ & $6.93 \pm 0.00$ & $22.0 \pm 0.00$ & $4.06 \pm 0.11$ & 0.0014 \\
\hline splQ13751 & LAMB3 & $14.62 \pm 2.70$ & $11.48 \pm 1.39$ & $8.5 \pm 0.71$ & $3.12 \pm 0.45$ & 0.0018 \\
\hline splQ96AG4 & LRRC59 & $24.42 \pm 0.61$ & $48.21 \pm 0.00$ & $15.0 \pm 1.41$ & $2.76 \pm 0.29$ & 0.0006 \\
\hline splP37802 & TAGLN2 & $48.05 \pm 5.01$ & $75.88 \pm 0.71$ & $76.5 \pm 0.71$ & $4.01 \pm 1.16$ & 0.0014 \\
\hline splO15231 & ZNF185 & $6.63 \pm 0.86$ & $10.45 \pm 1.44$ & $3.5 \pm 0.71$ & $3.60 \pm 0.05$ & 0.0145 \\
\hline splP08670 & VIM & $78.14 \pm 2.44$ & $69.52 \pm 0.30$ & $128.5 \pm 2.12$ & $6.78 \pm 0.66$ & 0.0009 \\
\hline splP07203 & GPX1 & $27.36 \pm 0.85$ & $84.24 \pm 0.00$ & $17.5 \pm 0.71$ & $4.32 \pm 0.48$ & 0.0013 \\
\hline splP46060 & RANGAP1 & $44.64 \pm 3.22$ & $53.24 \pm 0.12$ & $28.5 \pm 0.71$ & $1.66 \pm 0.02$ & 0.0079 \\
\hline splO00159-2 & MYO1C & $51.34 \pm 4.12$ & $34.29 \pm 0.48$ & $30.5 \pm 4.95$ & $3.26 \pm 1.68$ & 0.0058 \\
\hline splP04083 & ANXA1 & $52.37 \pm 6.22$ & $68.64 \pm 1.02$ & $91.5 \pm 9.19$ & $1.84 \pm 0.17$ & 0.0033 \\
\hline splQ92597 & NDRG1 & $20.49 \pm 0.41$ & $37.82 \pm 0.00$ & $20.0 \pm 1.41$ & $3.36 \pm 1.03$ & 0.0019 \\
\hline $\operatorname{trlB} 4 \mathrm{E} 0 \mathrm{H} 8$ & ITGA3 & $23.64 \pm 2.69$ & $16.20 \pm 2.59$ & $16.5 \pm 3.54$ & $2.09 \pm 0.54$ & 0.0087 \\
\hline $\operatorname{trlE7ESU5~}$ & ALB & $33.95 \pm 4.02$ & $41.66 \pm 1.03$ & $72.5 \pm 6.36$ & $2.26 \pm 0.13$ & 0.0023 \\
\hline trlD6RAK8 & $\mathrm{GC}$ & $9.94 \pm 2.45$ & $17.95 \pm 1.29$ & $10.0 \pm 1.41$ & $4.52 \pm 0.82$ & 0.0036 \\
\hline trlQ5T985 & ITIH2 & $11.62 \pm 0.23$ & $9.68 \pm 0.68$ & $9.0 \pm 0.00$ & $3.99 \pm 2.19$ & 0.0080 \\
\hline splP26639 & TARS & $77.47 \pm 5.34$ & $57.74 \pm 1.27$ & $68.5 \pm 2.12$ & $2.26 \pm 0.32$ & 0.0040 \\
\hline splP49589-3 & CARS & $38.44 \pm 3.73$ & $32.61 \pm 4.94$ & $18.0 \pm 2.90$ & $2.12 \pm 0.10$ & 0.0176 \\
\hline $\operatorname{trlF5H7K4~}$ & NCEH1 & $17.57 \pm 0.62$ & $26.90 \pm 0.79$ & $10.5 \pm 0.71$ & $2.25 \pm 0.61$ & 0.0241 \\
\hline splP02788 & LTF & $8.71 \pm 1.27$ & $9.86 \pm 0.00$ & $12.5 \pm 0.71$ & $7.29 \pm 0.62$ & 0.0188 \\
\hline splQ92621 & NUP205 & $33.73 \pm 1.67$ & $12.23 \pm 2.81$ & $20.5 \pm 3.54$ & $2.33 \pm 0.29$ & 0.0318 \\
\hline splQ9NZM1-6 & MYOF & $140.84 \pm 3.56$ & $47.85 \pm 2.60$ & $87.0 \pm 4.24$ & $2.24 \pm 0.16$ & 0.0062 \\
\hline splQ9Y2T3-3 & GDA & $39.77 \pm 1.44$ & $59.45 \pm 0.00$ & $38.0 \pm 1.41$ & $3.18 \pm 0.40$ & 0.0062 \\
\hline splP29317 & EPHA2 & $15.51 \pm 5.52$ & $11.99 \pm 2.03$ & $10.0 \pm 1.41$ & $3.46 \pm 0.34$ & 0.0083 \\
\hline splP80723 & BASP1 & $25.19 \pm 1.68$ & $72.03 \pm 4.05$ & $27.0 \pm 1.41$ & $7.59 \pm 2.89$ & 0.0101 \\
\hline splP48681 & NES & $23.27 \pm 1.01$ & $10.73 \pm 0.87$ & $12.5 \pm 0.71$ & $2.86 \pm 0.11$ & 0.0240 \\
\hline splP31947 & SFN & $20.68 \pm 0.27$ & $67.34 \pm 1.71$ & $37.0 \pm 1041$ & $2.37 \pm 0.65$ & 0.0190 \\
\hline splP16144-4 & ITGB4 & $41.89 \pm 1.24$ & $18.83 \pm 0.69$ & $25.5 \pm 0.71$ & $1.81 \pm 0.01$ & 0.0364 \\
\hline splQ01995 & TAGLN & $6.56 \pm 2.14$ & $25.13 \pm 3.88$ & $5.0 \pm 1.41$ & $2.31 \pm 0.35$ & 0.0373 \\
\hline splQ6P9B6 & KIAA1609 & $8.96 \pm 1.87$ & $16.01 \pm 0.62$ & $6.0 \pm 1.41$ & $3.02 \pm 0.20$ & 0.0326 \\
\hline
\end{tabular}


Table II. Countinued.

B, Downregulated differentially expressed proteins

\begin{tabular}{|c|c|c|c|c|c|c|}
\hline Accession & Protein & Unused score $^{\mathrm{a}}$ & Coverage, $\%^{\mathrm{a}}$ & Peptide $95 \% \mathrm{CL}^{\mathrm{a}}$ & iTRAQ rate & P-value \\
\hline splA0MZ66 & KIAA1598 & $50.71 \pm 0.09$ & $51.74 \pm 0.78$ & $31.0 \pm 2.12$ & $0.58 \pm 0.04$ & 0.0011 \\
\hline splO00232 & PSMD12 & $35.44 \pm 1.51$ & $47.03 \pm 2.02$ & $24.0 \pm 2.83$ & $0.47 \pm 0.04$ & 0.0029 \\
\hline splO14818 & PSMA7 & $29.16 \pm 1.11$ & $62.70 \pm 0.28$ & $23.0 \pm 2.83$ & $0.47 \pm 0.09$ & 0.0237 \\
\hline splO60749 & SNX2 & $20.85 \pm 4.76$ & $29.57 \pm 4.22$ & $16.0 \pm 2.12$ & $0.51 \pm 0.03$ & 0.0015 \\
\hline splO75533 & SF3B1 & $69 \pm 0.34$ & $36.5 \pm 2.60$ & $40.0 \pm 1.41$ & $0.41 \pm 0.00$ & 0.0014 \\
\hline splO95347 & SMC-2 & $56.22 \pm 3.49$ & $30.91 \pm 2.01$ & $37.0 \pm 4.95$ & $0.58 \pm 0.04$ & 0.0068 \\
\hline splO95573 & ACSL3 & $35.36 \pm 1.34$ & $36.04 \pm 0.10$ & $21.0 \pm 2.83$ & $0.58 \pm 0.07$ & 0.0096 \\
\hline splO95861 & BPNT1 & $23.27 \pm 0.62$ & $56.82 \pm 0.92$ & $15.0 \pm 0.71$ & $0.49 \pm 0.20$ & 0.0206 \\
\hline splP00390 & GSR & $17.07 \pm 0.64$ & $32.47 \pm 3.11$ & $11.0 \pm 0.00$ & $0.45 \pm 0.16$ & 0.0018 \\
\hline splP00505 & GOT2 & $53.15 \pm 1.19$ & $66.62 \pm 0.16$ & $39.0 \pm 4.24$ & $0.53 \pm 0.02$ & 0.0172 \\
\hline splP04040 & CAT & $34.55 \pm 2.03$ & $48.29 \pm 2.81$ & $22.0 \pm 0.71$ & $0.49 \pm 0.01$ & 0.0015 \\
\hline splP04075 & ALDOA & $97.5 \pm 2.79$ & $87.23 \pm 1.36$ & $212.0 \pm 7.07$ & $0.50 \pm 0.02$ & 0.0011 \\
\hline splP04792 & HSPB1 & $41.05 \pm 1.21$ & $79.51 \pm 8.28$ & $53.0 \pm 1.41$ & $0.23 \pm 0.23$ & 0.0034 \\
\hline splP05455 & SSB & $41.26 \pm 0.87$ & $51.10 \pm 1.21$ & $26.0 \pm 1.41$ & $0.49 \pm 0.03$ & 0.0034 \\
\hline splP06744 & GPI & $51.08 \pm 0.08$ & $55.19 \pm 1.52$ & $65.0 \pm 4.24$ & $0.41 \pm 0.10$ & 0.0078 \\
\hline splP07195 & LDHB & $33.47 \pm 2.41$ & $65.72 \pm 4.48$ & $73.0 \pm 1.41$ & $0.32 \pm 0.12$ & 0.0161 \\
\hline splP07339 & CTSD & $33.9 \pm 0.68$ & $50.85 \pm 4.98$ & $36.0 \pm 2.12$ & $0.54 \pm 0.04$ & 0.0010 \\
\hline splP07942 & LAMB1 & $42.6 \pm 3.96$ & $18.47 \pm 1.27$ & $27.0 \pm 3.54$ & $0.54 \pm 0.06$ & 0.0215 \\
\hline splP07954 & $\mathrm{FH}$ & $38.99 \pm 0.31$ & $50.09 \pm 0.42$ & $37.0 \pm 2.12$ & $0.58 \pm 0.05$ & 0.0065 \\
\hline splP09972 & ALDOC & $32.73 \pm 1.24$ & $70.05 \pm 2.33$ & $96.0 \pm 0.00$ & $0.21 \pm 0.01$ & 0.0020 \\
\hline splP11586 & MTHFD1 & $76.09 \pm 4.05$ & $50.16 \pm 4.99$ & $53.0 \pm 3.54$ & $0.60 \pm 0.04$ & 0.0055 \\
\hline splP12004 & PCNA & $27.15 \pm 3.05$ & $58.62 \pm 2.16$ & $37.0 \pm 3.54$ & $0.61 \pm 0.04$ & 0.0032 \\
\hline splP13611-2 & VCAN & $25.2 \pm 1.73$ & $8.053 \pm 0.53$ & $17.0 \pm 0.71$ & $0.37 \pm 0.12$ & 0.0065 \\
\hline splP13797 & PLS3 & $74.13 \pm 3.57$ & $67.69 \pm 1.01$ & $69.0 \pm 4.95$ & $0.24 \pm 0.07$ & 0.0037 \\
\hline splP21266 & GSTM3 & $33.26 \pm 1.87$ & $72.22 \pm 3.46$ & $21.0 \pm 1.41$ & $0.38 \pm 0.04$ & 0.0050 \\
\hline splP23786 & CPT2 & $27.57 \pm 5.16$ & $33.06 \pm 5.06$ & $17.0 \pm 3.54$ & $0.61 \pm 0.04$ & 0.0274 \\
\hline splP25789 & PSMA4 & $27.86 \pm 0.86$ & $65.13 \pm 1.63$ & $32.0 \pm 4.95$ & $0.58 \pm 0.00$ & 0.0133 \\
\hline splP27824 & CANX & $57.96 \pm 1.73$ & $62.92 \pm 3.71$ & $53.0 \pm 0.71$ & $0.31 \pm 0.10$ & 0.0016 \\
\hline splP37268 & FDFT1 & $17.91 \pm 0.20$ & $32.85 \pm 2.71$ & $12.0 \pm 2.12$ & $0.30 \pm 0.10$ & 0.0052 \\
\hline splP40937 & RFC5 & $14.34 \pm 1.11$ & $27.06 \pm 3.75$ & $12.0 \pm 2.12$ & $0.48 \pm 0.02$ & 0.0278 \\
\hline splP42166 & TMPO & $48.96 \pm 6.58$ & $57.28 \pm 2.55$ & $35.0 \pm 3.54$ & $0.28 \pm 0.04$ & 0.0004 \\
\hline splP42704 & LRPPRC & $129.11 \pm 3.57$ & $58.21 \pm 3.70$ & $95.0 \pm 12.02$ & $0.44 \pm 0.09$ & 0.0003 \\
\hline splP48449 & LSS & $28.14 \pm 3.34$ & $26.57 \pm 0.10$ & $16.0 \pm 0.71$ & $0.43 \pm 0.07$ & 0.0314 \\
\hline splP48735 & IDH2 & $36.91 \pm 0.72$ & $44.02 \pm 4.38$ & $21.0 \pm 0.71$ & $0.49 \pm 0.07$ & 0.0010 \\
\hline splP49321 & NASP & $50.23 \pm 3.21$ & $55.08 \pm 2.87$ & $38.0 \pm 2.12$ & $0.29 \pm 0.00$ & 0.0175 \\
\hline splP49327 & FASN & $200.88 \pm 9.07$ & $56.81 \pm 0.37$ & $167.0 \pm 3.54$ & $0.21 \pm 0.01$ & $<0.0001$ \\
\hline splP49419 & ALDH7A1 & $40.15 \pm 4.71$ & $48.24 \pm 0$ & $32.0 \pm 3.54$ & $0.49 \pm 0.00$ & 0.0238 \\
\hline splP51659 & HSD17B4 & $48.92 \pm 2.98$ & $50.87 \pm 0.86$ & $36.0 \pm 4.95$ & $0.47 \pm 0.06$ & 0.0345 \\
\hline splP52209 & PGD & $60 \pm 8.37$ & $66.97 \pm 9.81$ & $54.0 \pm 4.24$ & $0.48 \pm 0.11$ & 0.0226 \\
\hline splP52943 & CRIP2 & $16.69 \pm 0.41$ & $44.47 \pm 2.38$ & $12.0 \pm 1.41$ & $0.58 \pm 0.11$ & 0.0371 \\
\hline
\end{tabular}

apresented as mean \pm standard deviation. CL, confidence level; iTRAQ, isobaric tag for relative and absolute quantitation.

proteins may have been directly or indirectly regulated by miR-148a.
Verification of $i T R A Q M S$ results using $R T-q P C R$ and western blotting. Among the globally dysregulated group 


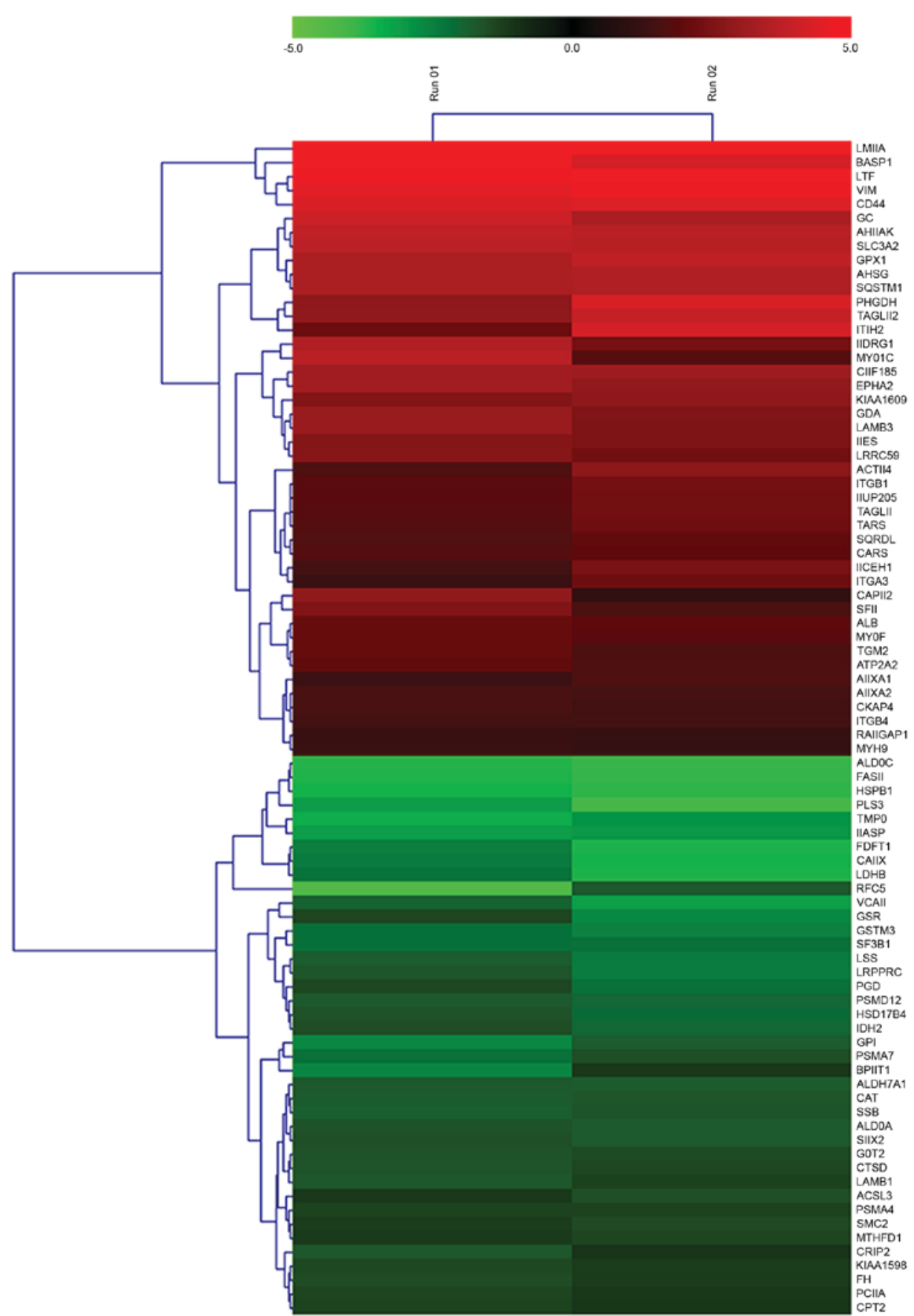

Figure 2. Heat map of 84 differentially expressed proteins in SPC-A-1 cells transfected with a microRNA-148a-inhibitor compared with cells transfected with a control oligonucleotide as determined by 2 identical mass spectrometry experiments.

of miR-148a-regulated proteins, a number of the proteins, including IDH2 (27), PHGDH (28), VIM (29), SLC3A2 (30), ACTN4 (31), MYH9 (32), ITGB1 (33), LAMB3 (34), were previously associated with migration in cancer cells. To verify the iTRAQ results, the mRNA levels of eight of the upregulated proteins (including MYH9, CD44, ITGB1, LAMB3, PHGDH, ACTN4, LMNA and VIM) and eight of the downregulated proteins (including PSMA7, MTHFD1, GSTM3, FH, HSPB1, LRPPRC, CPT2 and IDH2) were determined by RT-qPCR. As illustrated in Fig. 3A, the expression of the 16 genes was consistent with the MS analysis. Similar results were also demonstrated for the protein levels of LAMB3, VIM, PHGDH, ACTN4, FH,
HSPB1, IDH2, LDHB, FASN and CAT, as revealed by WB analysis (Fig. 3B).

Functional enrichment of miR-148a-regulated proteins. As demonstrated in Table III, the most significantly enriched KEGG pathways for the differentially expressed proteins were 'focal adhesion', 'arrhythmogenic right ventricular cardiomyopathy (ARVC)', 'ECM-receptor interaction', 'glutathione metabolism' and 'small cell lung cancer'. The proteins associated with each pathway are displayed in Table III.

GO annotation included the biological process, cellular component and molecular function GO categories. In 
Table III. Significantly enriched Kyoto Encyclopedia of Genes and Genomes pathways associated with the identified differentially expressed proteins.

\begin{tabular}{|c|c|c|c|}
\hline Pathway & Count & P-value & Associated genes \\
\hline $\begin{array}{l}\text { Arrhythmogenic right ventricular } \\
\text { cardiomyopathy }\end{array}$ & 6 & 0.0007 & $\begin{array}{l}\text { ATP2A2, ACTN4, LMNA, ITGB4, } \\
\text { ITGA3, ITGB1 }\end{array}$ \\
\hline ECM-receptor interaction & 6 & 0.0012 & $\begin{array}{l}\text { LAMB3, CD44, ITGB4, ITGA3, } \\
\text { LAMB1, ITGB1 }\end{array}$ \\
\hline Glutathione metabolism & 5 & 0.0013 & GSR, GPX1, GSTM3, PGD, IDH2 \\
\hline Pentose phosphate pathway & 4 & 0.0017 & ALDOA, GPI, ALDOC, PGD \\
\hline Glycolysis/Gluconeogenesis & 5 & 0.0025 & $\begin{array}{l}\text { ALDOA, GPI, LDHB, ALDH7A1, } \\
\text { ALDOC }\end{array}$ \\
\hline Hypertrophic cardiomyopathy (HCM) & 5 & 0.0087 & $\begin{array}{l}\text { ATP2A2, LMNA, ITGB4, ITGA3, } \\
\text { ITGB1 }\end{array}$ \\
\hline Dilated cardiomyopathy & 5 & 0.0114 & $\begin{array}{l}\text { ATP2A2, LMNA, ITGB4, ITGA3, } \\
\text { ITGB1 }\end{array}$ \\
\hline Focal adhesion & 7 & 0.0120 & $\begin{array}{l}\text { LAMB3, ACTN4, ITGB4, ITGA3, } \\
\text { LAMB1, CAPN2, ITGB1 }\end{array}$ \\
\hline Small cell lung cancer & 4 & 0.0465 & LAMB3, ITGA3, LAMB1, ITGB 1 \\
\hline
\end{tabular}

ATP2A2, ATPase sarcoplasmic/endoplasmic reticulum $\mathrm{Ca}^{2+}$ transporting 2; ACTN4, $\alpha$-actin 4; LMNA, lamin A/C; ITGB4, integrin subunit $\beta 4$; ITGA3, integrin subunit $\alpha 3$; ITGB1, integrin subunit $\beta 1$; LAMB3, laminin subunit $\beta 3$; CD44, cluster of differentiation 44 ; LAMB1, laminin subunit $\beta 1$; GSR, glutathione-disulfide reductase; GPX1, glutathione peroxidase 1; GSTM3, glutathione S-transferase $\mu 3$; PGD, phosphogluconate dehydrogenase; IDH2, isocitrate dehydrogenase $\left(\mathrm{NADP}^{+}\right)$2; ALDOA, aldolase, fructose-bisphosphonate A; GPI, glucose-6-phophate isomerase; ALDOC, aldolase, fructose-bisphosphonate C; ALDH7A1, aldehyde dehydrogenase 7 family member A1; CAPN2, caplain 2.
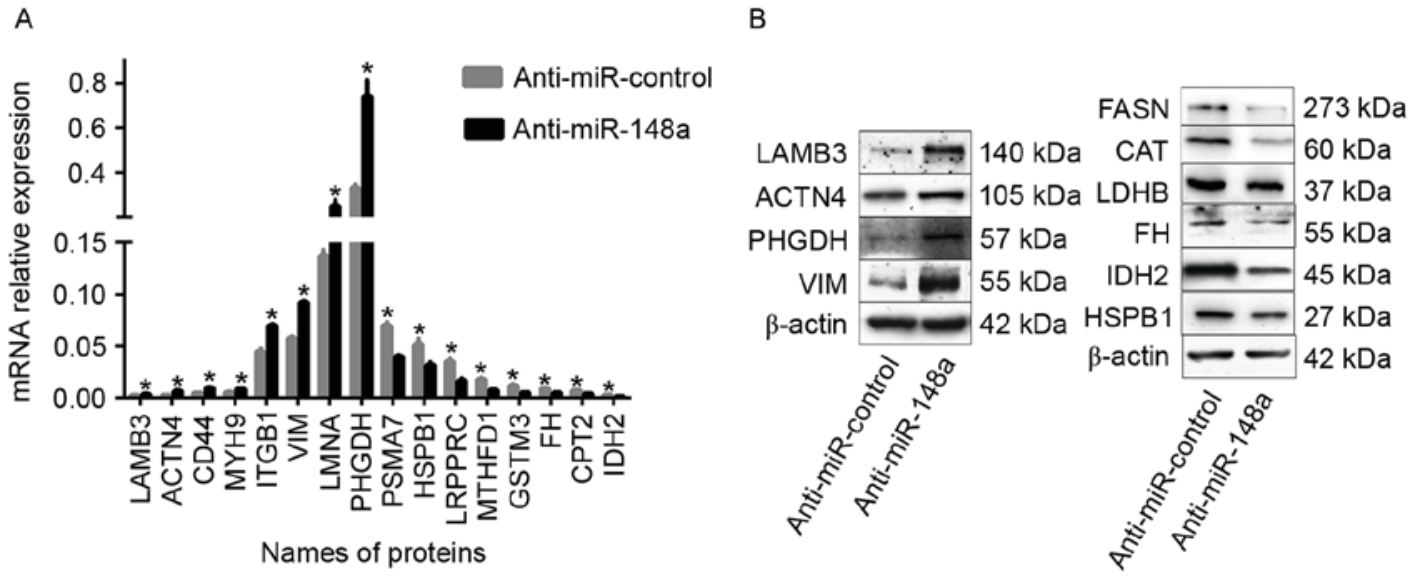

Figure 3. Identified differentially expressed proteins verification by RT-qPCR and western blot analysis. (A) MicroRNA levels of 8 upregulated proteins (MYH9, CD44, ITGB1, LAMB3, PHGDH, ACTN4, LMNA and VIM) and 8 downregulated proteins (PSMA7, MTHFD1, GSTM3, FH, HSPB1, LRPPRC, CPT2 and IDH2) were determined by RT-qPCR following the transfection of SPC-A-1 cells with an miR-148a inhibitor or control oligonucleotide. $\beta$-actin served as an internal control. (B) Protein levels of LAMB3, VIM, PHGDH, ACTN4, FH, HSPB1, IDH2, LDHB, FASN and CAT were determined by western blot analysis following the transfection of SPC-A-1 cells with a miR-148a inhibitor or control oligonucleotide. $\beta$-actin served as an internal control. The data were representative of three independent experiments. " $\mathrm{P}<0.05$. RT-qPCR, reverse transcription-quantitative polymerase chain reaction; MYH9, myosin heavy chain 9; CD44, cluster of differentiation 44; ITGB1, integrin $\beta 1$; LAMB3, laminin subunit $\beta 3$; PHGDH, phosphoglycerate dehydrogenase; ACTN4, $\alpha$-actinin-4; LMNA, lamin A/C; VIM, vimentin; PSMA7, proteasome subunit $\alpha$ 7; MTHFD1, methylenetetrahydrofolate dehydrogenase; GSTM3, glutathione S-transferase M3; FH, fumarate hydratase; HSPB1, heat shock protein $\beta 1$; LRPPRC, leucine rich pentatricopeptide repeat; CPT2, carnitine palmitoyltransferase 2; IDH2, isocitrate dehydrogenase 2; LDHB, lactate dehydrogenase B; FASN, fatty acid synthase; CAT, catalase.

Biological Process, the top 3 were 'oxidation reduction', 'coenzyme metabolic process' and 'cofactor metabolic process'. In cellular component, differentially expressed proteins were most likely to be associated with 'mitochondrion', 'organelle envelope', 'envelope' and 'cell fraction'. Molecular Function analysis indicated that the proteins were chiefly involved in 'identical protein binding', 'cofactor binding', 'cytoskeletal protein binding' and 'actin 
A

B
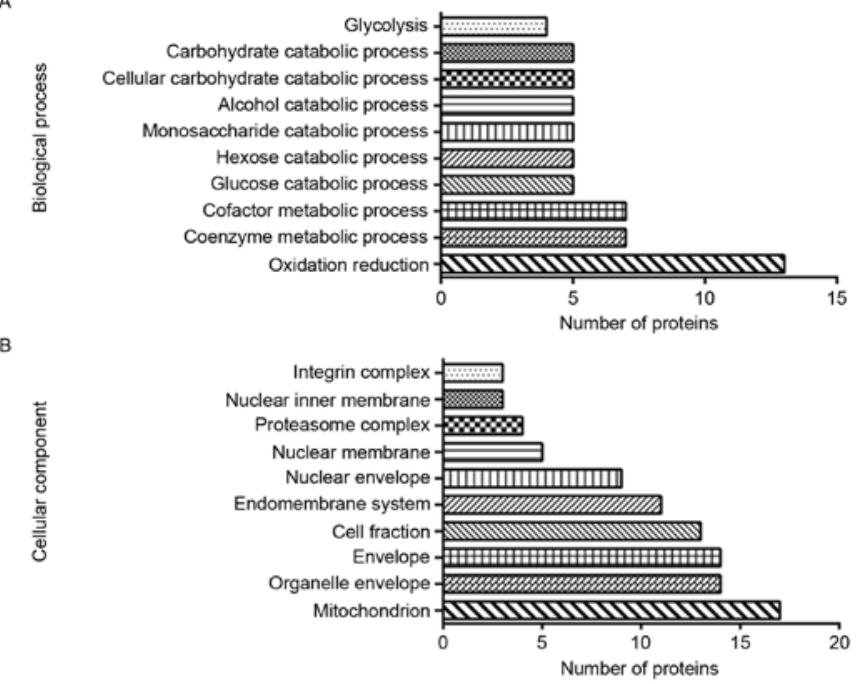

c

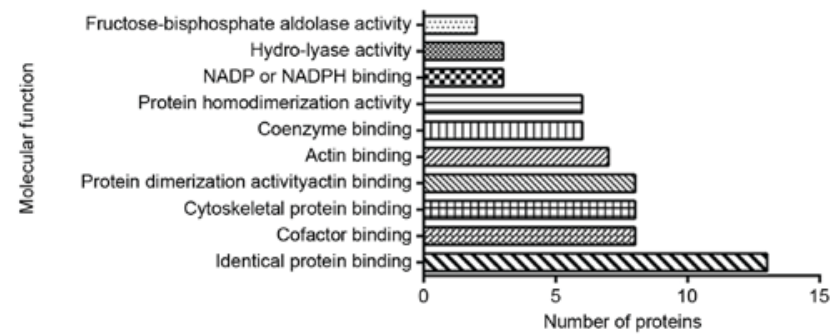

Figure 4 . The 84 differentially expressed proteins were uploaded to the Database for Annotation, Visualization and Integrated Discovery for GO analysis. The histograms demonstrate the top 10 terms by count for (A) biological process, (B) cellular component and (C) molecular function. GO, Gene Ontology.

binding'. The results of GO annotation are illustrated in Fig. 4.

Protein-protein interaction network. To elucidate the protein-protein interactions of the globally differentially expressed proteins in the SPC-A-1 cells treated with a miR-148a inhibitor, a STRING database search was performed. The database identified interactions for 81 proteins at the medium confidence level (STRING score, 0.4). The network is displayed in Fig. 5.

GO analysis in STRING revealed that the GO terms most significantly associated with the differentially expressed proteins in the network were 'small molecule metabolic process', 'epithelium development', 'carboxylic acid metabolic process', 'oxoacid metabolic process' and 'organonitrogen compound metabolic process'. GSR, IDH2, ALDH7A1, GOT2, PMSA4 and PMSA7 were associated with 'small molecule metabolic process', VIM, LAMB3, CAT, TAGLN and TAGLN2 with 'epithelium development' and CARS, TARS, GPI, ALDOA and PGD with 'carboxylic acid metabolic process'.

\section{Discussion}

It has been identified that miR-148a serves important functions in various types of cancer $(35,36)$. Our previous study demonstrated that miR-148a exerted metastasis-suppressive effects in NSCLC, suppressing NSCLC invasion and metastasis in vitro and in vivo (19). These results have been corroborated by other studies $(21,37)$, indicating that miR-148a may provide a promising therapeutic target against NSCLC. However, the molecular mechanisms underlying the metastasis-suppressive effects of miR-148a on NSCLC remain poorly understood. An increasing number of researchers employ proteomic strategies to seek downstream putative targets and molecular mechanisms modulated by miRNAs (16-18). In the present study, iTRAQ technology combined with NanoLC-MS/MS was used to analyze the global protein expression profiles of SPC-A-1 cells treated with the miR-148a inhibitor and control, and therefore, to explore the molecular mechanisms modulated by miR-148a. A total of 84 differentially expressed proteins were identified, of which 44 proteins were upregulated and 40 were downregulated. A number of these miR-148a-regulated proteins may be associated with cancer migration.

The protein expression levels of four upregulated proteins (LAMB3, VIM, PHGDH and ACTN4) and six downregulated proteins (FH, HSPB1, IDH2, LDHB, FASN and CAT) were examined by WB analysis; all results were consistent with the MS results. LAMB3 is a member of the laminin family of large glycoproteins, present in various types of basement membrane (BM) (38). LAMB3 is associated with the metastasis of a number of types of tumor (39-41). Concordantly, our previous study (34) demonstrated that the protein expression level of LAMB3 was higher in NSCLC compared with non-cancerous adjacent tissues and that LAMB3 expression was associated with lymphatic metastasis. LAMB3 may be a suitable therapeutic target in NSCLC. Vimentin is responsible for maintaining cell shape and integrity of the cytoplasm, and stabilizing cytoskeletal interactions. It is a vital mesenchymal marker that participates in the endothelial-mesenchymal transition (EndMT) and tumor metastasis (42). The upregulation of vimentin in NSCLC was detected in a previous study (43). $\mathrm{PHGDH}$ is an enzyme that catalyzes the $\mathrm{NAD}^{+}$-dependent conversion of 3-phosphoglycerate to phosphohydroxypyruvate. The conversion is the first step in the de novo serine synthesis pathway (44). In patients with gastric cancer, high PHGDH protein expression is associated with a poor prognosis (45). In addition, PHGDH expression may promote tumor initiation and metastasis in breast cancer (28). However, the functions of PHGDH in NSCLC are not clear. ACTN4 participates in the formation of the filopodia and lamellipodia, which are important for cell motility, by regulating the flexibility of actin filaments (46). It has been reported that ACTN4 may promote the metastatic potential of lung cancer (31).

With regard to the six verified downregulated proteins, IDH2 is a mitochondrial NADP-dependent isocitrate dehydrogenase that functions variably in different types of cancer. It has been reported that IDH2 inhibited the invasion of hepatocellular carcinoma cells via the regulation of MMP9, and therefore acted as a tumor suppressor (47). By contrast, in another study the overexpression of IDH2 promoted cell growth in colon cancer (48). It has been suggested that $\mathrm{FH}$ suppresses the tumorigenesis, development and invasion of various types of cancer (49). FH mRNA expression and protein expression have been observed to be significantly lower in lung cancer cells and tissue samples (50). However, the molecular mechanisms for the tumor suppressive functions of $\mathrm{FH}$ are uncharacterized. HSPB1 has been reported as a multifunctional molecule; for example, the expression level of HSPB1 is higher 


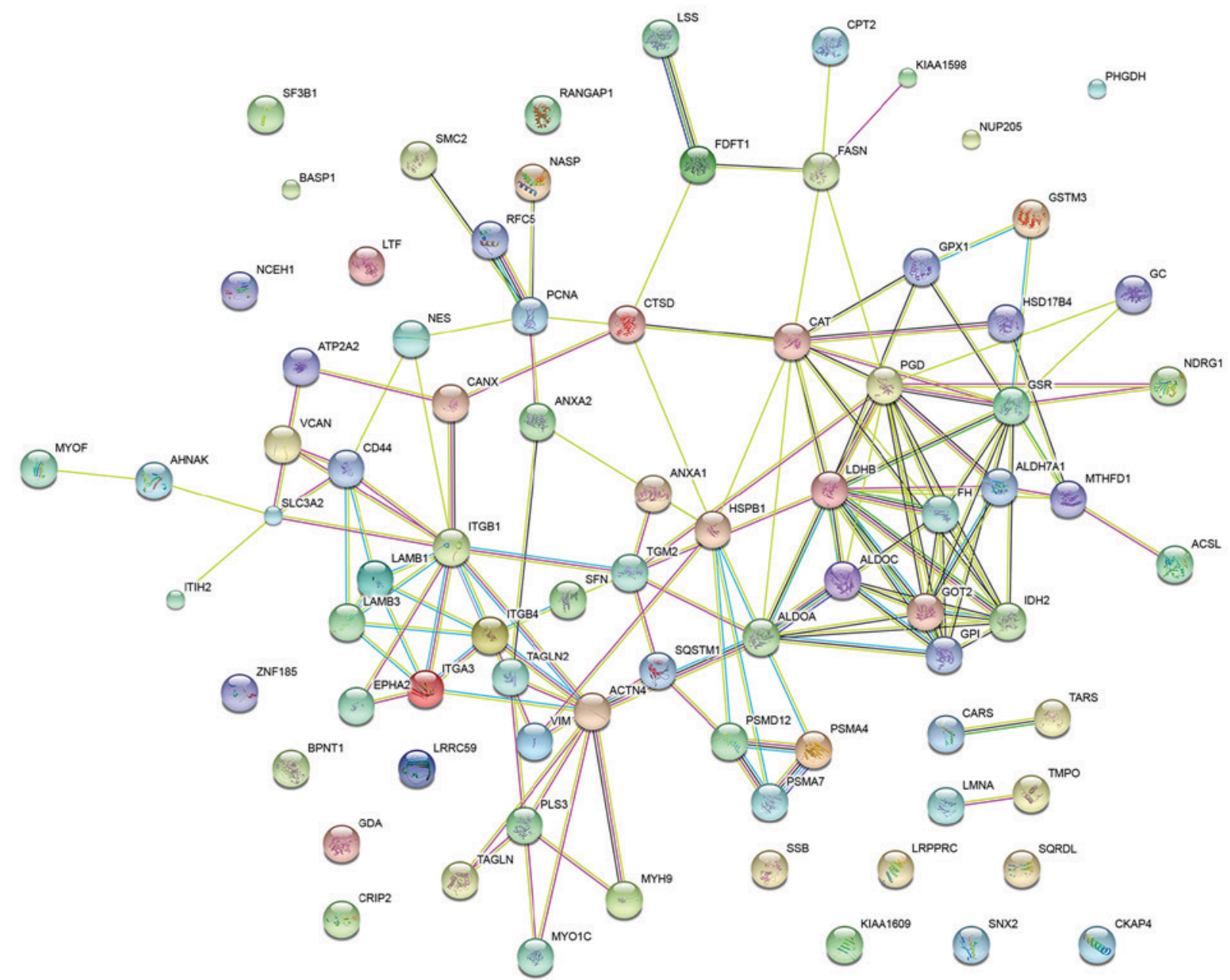

Figure 5. The 84 differentially expressed proteins in SPC-A-1 cells transfected with a microRNA-148a-inhibitor were submitted to Search Tool for the Retrieval of Interacting Genes for the prediction of protein-protein interactions. Colored nodes represent query proteins and first shell of interactions. Edge colors represent various interaction types: Light red and light blue represent known interactions, whereas green, red and blue represent predicted interactions

in nasopharyngeal carcinoma compared with the adjacent non-tumor tissues (51). HSPB1 has also been demonstrated to suppress pulmonary fibrosis and lung tumorigenesis through inhibiting the EndMT. However, the association of HSPB1 deficiency with lung metastasis is unknown (52). The EndMT is characterized by the loss of endothelial marker expression and the acquisition of a mesenchymal or fibroblastic phenotype, including the production of fibroblastic protein-1, type I collagen and smooth muscle actin, resulting in cells that have invasive and migratory potential $(53,54)$. Cancer-associated fibroblasts (CAFs) have been indicated to promote tumor cell proliferation by inducing changes in the tumor microenvironment (55). The EndMT is an important source of CAFs in pancreatic carcinoma (56) and enhances the invasiveness of infected endothelial cells, contributing to malignant progression (57). A previous study suggested the EndMT may be necessary for metastatic extravasation in brain endothelial cells (58). TGF $\beta$-associated signals have been linked to the EndMT in cancer (59); however, the mechanisms of EndMT in cancer are incompletely characterized and require further investigation.

Lactate dehydrogenase B (LDHB) has been reported as a suppressor of glycolysis and pancreatic cancer progression (60). However, another study indicated that the high expression of LDHB was crucial for osteosarcoma cell growth, proliferation, migration and invasion, and that it predicted a poor prognosis in patients with osteosarcoma (61). A previous study indicated that fatty acid synthase promoted the proliferation of breast cancer cells, and was a primary target of miR-15a and miR-16-1 in breast cancer (62). An association between high LDHB expression and reduced survival time has been suggested for patients with NSCLC (63). Catalase is a key antioxidant enzyme that protects against oxidative stress; it has been reported to be a tumor suppressor that inhibits the migration and invasion of lung cancer cells (64), and it may therefore serve as a therapeutic target for lung cancer.

There has been increasing research regarding the epigenetic modifications in the etiology of human diseases, including various types of cancer. DNA methylation of $\mathrm{CpG}$ islands is established and maintained by DNA methyltransferases (DNMTs), including DNMT1, DNMT3A and DNMT3B (65). There may be an association between the expression of DNMT1 and miR-148a; the overexpression of DNMT1 may induce the hypermethylation of the miR-148a promoter, and DNMT1 may be a direct target for inhibition by miR-148a. This regulation loop has been reported in breast and gastric cancer $(22,66)$. However, to the best of our knowledge, there are no studies regarding the association between miR-148a and DNMT1 in 
lung cancer, and although DNMT was detected in the present study, there was no alteration to its expression subsequent to the inhibition of miR-148a. The lack of difference in DNMT1 protein expression in the present study may be a discrepancy caused by tumor heterogeneity. Despite the progress in understanding the molecular mechanisms of miR-148a and its function in different types of cancer, the topic remains ambiguous, and further investigation is required.

In the present study, differentially expressed proteins were identified using a proteomics strategy in SPC-A-1 cells after transfection with the miR-148a inhibitor; the differentially expressed proteins were then analyzed using bioinformatics tools. The results may provide a deeper insight into the molecular mechanisms underlying the metastasis-suppressive effect of miR-148a on NSCLC. The targets of miR-148a may directly or indirectly interact with tumor-associated proteins to affect the metastasis of NSCLC via the pathways identified in the bioinformatics analysis. The present study also supports the possibility that miR-148a may be a potential therapeutic target against NSCLC.

\section{Acknowledgements}

The present study was supported by the Shanghai Natural Science Foundation (grant no. 12ZR1428900) and the State Key Laboratory of Oncogenes and Related Genes Research Fund (grant no. 91-15-09).

\section{References}

1. Torre LA, Bray F, Siegel RL, Ferlay J, Lortet-Tieulent J and Jemal A Global cancer statistics, 2012. CA Cancer J Clin 65: 87-108, 2015.

2. Siegel RL, Fedewa SA, Miller KD, Goding-Sauer A, Pinheiro PS, Martinez-Tyson D and Jemal A: Cancer statistics for Hispanics/Latinos, 2015. CA Cancer J Clin 65: 457-480, 2015.

3. Mizuno K, Mataki H, Seki N, Kumamoto T, Kamikawaji K and Inoue $\mathrm{H}$ : MicroRNAs in non-small cell lung cancer and idiopathic pulmonary fibrosis. J Hum Genet 62: 57-65, 2016.

4. Molina JR, Yang P, Cassivi SD, Schild SE and Adjei AA Non-small cell lung cancer: Epidemiology, risk factors, treatment, and survivorship. Mayo Clin Proc 83: 584-594, 2008.

5. Hanahan D and Weinberg RA: The hallmarks of cancer. Cell 100: $57-70,2000$

6. Ambros V: The functions of animal microRNAs. Nature 431: 350-355, 2004

7. Bartel DP: MicroRNAs: Target recognition and regulatory functions. Cell 136: 215-233, 2009.

8. Yu T, Li J, Yan M, Liu L, Lin H, Zhao F, Sun L, Zhang Y, Cui Y, Zhang F, et al: MicroRNA-193a-3p and -5p suppress the metastasis of human non-small-cell lung cancer by downregulating the ERBB4/PIK3R3/mTOR/S6K2 signaling pathway. Oncogene 34: 413-423, 2015.

9. Xue J, Chi Y, Chen Y, Huang S, Ye X, Niu J, Wang W, Pfeffer LM, Shao ZM, Wu ZH and Wu J: MiRNA-621 sensitizes breast cancer to chemotherapy by suppressing FBXO11 and enhancing p53 activity. Oncogene 35: 448-458, 2016.

10. Iorio MV and Croce CM: MicroRNA dysregulation in cancer: Diagnostics, monitoring and therapeutics. A comprehensive review. EMBO Mol Med 9: 852, 2017.

11. Shen B, Yu S, Zhang Y, Yuan Y, Li X, Zhong J and Feng J: miR-590-5p regulates gastric cancer cell growth and chemosensitivity through RECK and the AKT/ERK pathway. Onco Targets Ther 9: 6009-6019, 2016.

12. Li J, Wu H, Li W, Yin L, Guo S, Xu X, Ouyang Y, Zhao Z, Liu S, Tian Y, et al: Downregulated miR-506 expression facilitates pancreatic cancer progression and chemoresistance via SPHK1/Akt/NF- $\mathrm{BB}$ signaling. Oncogene 35: 5501-5514, 2016.

13. Ai J, Huang H, Lv X, Tang Z, Chen M, Chen T, Duan W, Sun H, Li Q, Tan R, et al: FLNA and PGK1 are two potential markers for progression in hepatocellular carcinoma. Cell Physiol Biochem 27: 207-216, 2011.
14. Mueller LN, Brusniak MY, Mani DR and Aebersold R: An assessment of software solutions for the analysis of mass spectrometry based quantitative proteomics data. J Proteome Res 7: 51-61, 2008.

15. Lin HC, Zhang FL, Geng Q, Yu T, Cui YQ, Liu XH, Li J, Yan MX, Liu L, He XH, et al: Quantitative proteomic analysis identifies CPNE3 as a novel metastasis-promoting gene in NSCLC. J Proteome Res 12: 3423-3433, 2013.

16. Kaller M, Liffers ST, Oeljeklaus S, Kuhlmann K, Röh S, Hoffmann R, Warscheid B and Hermeking H: Genome-wide characterization of miR-34a induced changes in protein and mRNA expression by a combined pulsed SILAC and microarray analysis. Mol Cell Proteomics 10: M111.010462, 2011. doi: $10.1074 / \mathrm{mcp} . M 111.010462$

17. Baek D, Villen J, Shin C, Camargo FD, Gygi SP and Bartel DP: The impact of microRNAs on protein output. Nature 455: 64-71, 2008.

18. Litholdo CG Jr, Parker BL, Eamens AL, Larsen MR, Cordwell SJ and Waterhouse PM: Proteomic identification of putative microRNA394 target genes in arabidopsis thaliana identifies major latex protein family members critical for normal development. Mol Cell Proteomics 15: 2033-2047, 2016.

19. Li J, Yu T, Cao J, Liu L, Liu Y, Kong HW, Zhu MX, Lin HC, Chu DD, Yao M and Yan MX: MicroRNA-148a suppresses invasion and metastasis of human non-small-cell lung cancer. Cell Physiol Biochem 37: 1847-1856, 2015.

20. Livak KJ and Schmittgen TD: Analysis of relative gene expression data using real-time quantitative PCR and the 2(-Delta Delta C(T)) method. Methods 25: 402-408, 2001.

21. Joshi P, Jeon YJ, Lagana A, Middleton J, Secchiero P, Garofalo M and Croce CM: MicroRNA-148a reduces tumorigenesis and increases TRAIL-induced apoptosis in NSCLC. Proc Natl Acad Sci USA 112: 8650-8655, 2015.

22. Zhu A, Xia J, Zuo J, Jin S, Zhou H, Yao L, Huang H and Han Z: MicroRNA-148a is silenced by hypermethylation and interacts with DNA methyltransferase 1 in gastric cancer. Med Oncol 29: 2701-2709, 2012.

23. Zhang SL and Liu L: MicroRNA-148a inhibits hepatocellular carcinoma cell invasion by targeting sphingosine-1-phosphate receptor 1. Exp Ther Med 9: 579-584, 2015.

24. Zhang R, Li M, Zang W, Chen X, Wang Y, Li P, Du Y, Zhao G and $\mathrm{Li} \mathrm{L}$ : miR-148a regulates the growth and apoptosis in pancreatic cancer by targeting CCKBR and Bcl-2. Tumour Biol 35: 837-844, 2014.

25. Jiang Q, He M, Ma MT, Wu HZ, Yu ZJ, Guan S, Jiang LY, Wang Y, Zheng DD, Jin F and Wei MJ: MicroRNA-148a inhibits breast cancer migration and invasion by directly targeting WNT-1. Oncol Rep 35: 1425-1432, 2016.

26. Sakamoto N, Naito Y, Oue N, Sentani K, Uraoka N, Zarni Oo H, Yanagihara K, Aoyagi K, Sasaki H and Yasui W: MicroRNA-148a is downregulated in gastric cancer, targets MMP7, and indicates tumor invasiveness and poor prognosis. Cancer Sci 105: 236-243, 2014.

27. Yi WR, Li ZH, Qi BW, Ernest ME, Hu X and Yu AX: Downregulation of IDH2 exacerbates the malignant progression of osteosarcoma cells via increased NF- $\mathrm{KB}$ and MMP-9 activation. Oncol Rep 35: 2277-2285, 2016.

28. Samanta D, Park Y, Andrabi SA, Shelton LM, Gilkes DM and Semenza GL: PHGDH expression is required for mitochondrial redox homeostasis, breast cancer stem cell maintenance and lung metastasis. Cancer Res 76: 4430-4442, 2016.

29. Zhu QS, Rosenblatt K, Huang KL, Lahat G, Brobey R, Bolshakov S, Nguyen T, Ding Z, Belousov R, Bill K, et al: Vimentin is a novel AKT1 target mediating motility and invasion. Oncogene 30: 457-470, 2011.

30. Chen CL, Chung T, Wu CC, Ng KF, Yu JS, Tsai CH, Chang YS, Liang Y, Tsui KH and Chen YT: Comparative tissue proteomics of microdissected specimens reveals novel candidate biomarkers of bladder cancer. Mol Cell Proteomics 14: 2466-2478, 2015.

31. Gao Y, Li G, Sun L, He Y, Li X, Sun Z, Wang J, Jiang Y and Shi J: ACTN4 and the pathways associated with cell motility and adhesion contribute to the process of lung cancer metastasis to the brain. BMC Cancer 15: 277, 2015.

32. Zhou W, Fan MY, Wei YX, Huang S, Chen JY and Liu P: The expression of MYH9 in osteosarcoma and its effect on the migration and invasion abilities of tumor cell. Asian Pac J Trop Med 9: 597-600, 2016.

33. Qin Q, Wei F, Zhang J and Li B: miR-134 suppresses the migration and invasion of non-small cell lung cancer by targeting ITGB1. Oncol Rep 37: 823-830, 2017. 
34. Wang XM, Li J, Yan MX, Liu L, Jia DS, Geng Q, Lin HC, $\mathrm{He} \mathrm{XH}, \mathrm{Li} J J$ and Yao M: Integrative analyses identify osteopontin, LAMB3 and ITGB1 as critical pro-metastatic genes for lung cancer. PLoS One 8: e55714, 2013.

35. Zhang H, Wang Y, Xu T, Li C, Wu J, He Q, Wang G, Ding C, Liu K, Tang H and Ji F: Increased expression of microRNA-148a in osteosarcoma promotes cancer cell growth by targeting PTEN. Oncol Lett 12: 3208-3214, 2016.

36. Lombard AP, Mooso BA, Libertini SJ, Lim RM, Nakagawa RM, Vidallo KD, Costanzo NC, Ghosh PM and Mudryj M: miR-148a dependent apoptosis of bladder cancer cells is mediated in part by the epigenetic modifier DNMT1. Mol Carcinog 55: 757-767, 2016.

37. Li J, Song Y, Wang Y, Luo J and Yu W: MicroRNA-148a suppresses epithelial-to-mesenchymal transition by targeting ROCK1 in non-small cell lung cancer cells. Mol Cell Biochem 380: 277-282, 2013.

38. Simon-Assmann P, Orend G, Mammadova-Bach E, Spenlé C and Lefebvre O: Role of laminins in physiological and pathological angiogenesis. Int J Dev Biol 55: 455-465, 2011

39. Tanis T, Cincin ZB, Gokcen-Rohlig B, Bireller ES, Ulusan M, Tanyel CR and Cakmakoglu B: The role of components of the extracellular matrix and inflammation on oral squamous cell carcinoma metastasis. Arch Oral Biol 59: 1155-1163, 2014.

40. Yamamoto N, Kinoshita T, Nohata N, Itesako T, Yoshino H, Enokida H, Nakagawa M, Shozu M and Seki N: Tumor suppressive microRNA-218 inhibits cancer cell migration and invasion by targeting focal adhesion pathways in cervical squamous cell carcinoma. Int J Oncol 42: 1523-1532, 2013.

41. Kinoshita T, Hanazawa T, Nohata N, Kikkawa N, Enokida H, Yoshino H, Yamasaki T, Hidaka H, Nakagawa M, Okamoto Y and Seki N: Tumor suppressive microRNA-218 inhibits cancer cell migration and invasion through targeting laminin-332 in head and neck squamous cell carcinoma. Oncotarget 3: 1386-1400, 2012.

42. Thiery JP, Acloque H, Huang RY and Nieto MA: Epithelial-mesenchymal transitions in development and disease Cell 139: 871-890, 2009.

43. Tadokoro A, Kanaji N, Liu D, Yokomise H, Haba R, Ishii T, Takagi T, Watanabe N, Kita N, Kadowaki N and Bandoh S: Vimentin regulates invasiveness and is a poor prognostic marker in non-small cell lung cancer. Anticancer Res 36: 1545-1551, 2016.

44. Unterlass JE, Basle A, Blackburn TJ, Tucker J, Cano C, Noble ME and Curtin NJ: Validating and enabling phosphoglycerate dehydrogenase (PHGDH) as a target for fragment-based drug discovery in PHGDH-amplified breast cancer. Oncotarget, 13139-13153, 2018

45. Xian Y, Zhang S, Wang X, Qin J, Wang W and Wu H: Phosphoglycerate dehydrogenase is a novel predictor for poor prognosis in gastric cancer. Onco Targets Ther 9: 5553-5560, 2016.

46. Shao H, Wang JH, Pollak MR and Wells A: $\alpha$-actinin-4 is essential for maintaining the spreading, motility and contractility of fibroblasts. PLoS One 5: e13921, 2010

47. Tian GY, Zang SF, Wang L, Luo Y, Shi JP and Lou GQ: Isocitrate dehydrogenase 2 suppresses the invasion of hepatocellular carcinoma cells via matrix metalloproteinase 9. Cell Physio Biochem 37: 2405-2414, 2015.

48. Lv Q, Xing S, Li Z, Li J, Gong P, Xu X, Chang L, Jin X, Gao F, $\mathrm{Li}$ W, et al: Altered expression levels of IDH2 are involved in the development of colon cancer. Exp Ther Med 4: 801-806, 2012.

49. Tomlinson IP, Alam NA, Rowan AJ, Barclay E, Jaeger EE, Kelsell D, Leigh I, Gorman P, Lamlum H, Rahman S, et al: Germline mutations in FH predispose to dominantly inherited uterine fibroids, skin leiomyomata and papillary renal cell cancer. Nat Genet 30: 406-410, 2002.
50. Ming Z, Jiang M, Li W, Fan N, Deng W, Zhong Y, Zhang Y, Zhang $Q$ and Yang S: Bioinformatics analysis and expression study of fumarate hydratase in lung cancer. Thorac Cancer 5: 543-549, 2014

51. Cai XZ, Zeng WQ, Xiang Y, Liu Y, Zhang HM, Li H, She S, Yang M, Xia K and Peng SF: iTRAQ-based quantitative proteomic analysis of nasopharyngeal carcinoma. J Cell Biochem 116: 1431-1441, 2015.

52. Choi SH, Nam JK, Kim BY, Jang J, Jin YB, Lee HJ, Park S, Ji YH, Cho $J$ and Lee YJ: HSPB1 inhibits the endothelial-to-mesenchymal transition to suppress pulmonary fibrosis and lung tumorigenesis. Cancer Res 76: 1019-1030, 2016.

53. Potenta S, Zeisberg E and Kalluri R: The role of endothelial-to-mesenchymal transition in cancer progression. Br J Cancer 99: 1375-1379, 2008.

54. Lin F, Wang N and Zhang TC: The role of end othelial-mesenchymal transition in development and pathological process. IUBMB Life 64: 717-723, 2012.

55. Augsten M: Cancer-associated fibroblasts as another polarized cell type of the tumor microenvironment. Front Oncol 4: 62, 2014.

56. Zeisberg EM, Potenta S, Xie L, Zeisberg M and Kalluri R: Discovery of endothelial-to-mesenchymal transition as a source for carcinoma-associated fibroblasts. Cancer Res 67 10123-10128, 2007.

57. Gasperini P, Espigol-Frigole G, McCormick PJ, Salvucci O, Maric D, Uldrick TS, Polizzotto MN, Yarchoan R and Tosato G: Kaposi sarcoma herpesvirus promotes endothelial-to-mesenchymal transition through notch-dependent signaling. Cancer Res 72: 1157-1169, 2012.

58. Krizbai IA, Gasparics Á, Nagyőszi P, Fazakas C, Molnár J, Wilhelm I, Bencs R, Rosivall L and Sebe A: Endothelial-mesenchymal transition of brain endothelial cells: Possible role during metastatic extravasation. PLoS One 10: e0123845, 2015.

59. van Meeteren LA and ten Dijke P: Regulation of endothelial cell plasticity by TGF- $\beta$. Cell Tissue Res 347: 177-186, 2012.

60. Cui J, Quan M, Jiang W, Hu H, Jiao F, Li N, Jin Z, Wang L, Wang Y and Wang L: Suppressed expression of LDHB promotes pancreatic cancer progression via inducing glycolytic phenotype. Med Oncol 32: 143, 2015.

61. Li C, Chen Y, Bai P, Wang J, Liu Z, Wang T and Cai Q: LDHB may be a significant predictor of poor prognosis in osteosarcoma. Am J Transl Res 8: 4831-4843, 2016.

62. Wang J, Zhang X, Shi J, Cao P, Wan M, Zhang Q, Wang Y, Kridel SJ, Liu W, Xu J, et al: Fatty acid synthase is a primary target of miR-15a and miR-16-1 in breast cancer. Oncotarget 7: 78566-78576, 2016.

63. Cerne D, Zitnik IP and Sok M: Increased fatty acid synthase activity in non-small cell lung cancer tissue is a weaker predictor of shorter patient survival than increased lipoprotein lipase activity. Arch Med Res 41: 405-409, 2010.

64. Tsai JY, Lee MJ, Dah-Tsyr Chang M and Huang H: The effect of catalase on migration and invasion of lung cancer cells by regulating the activities of cathepsin $\mathrm{S}, \mathrm{L}$ and $\mathrm{K}$. Exp Cell Res 323: 28-40, 2014.

65. Zhang W and $\mathrm{Xu}$ J: DNA methyltransferases and their roles in tumorigenesis. Biomark Res 5: 1, 2017.

66. Xu Q, Jiang Y, Yin Y, Li Q, He J, Jing Y, Qi YT, Xu Q, Li W, Lu B, et al: A regulatory circuit of miR-148a/152 and DNMT1 in modulating cell transformation and tumorangiogenesis through IGF-IR and IRS1. J Mol Cell Biol 5: 3-13, 2013. 